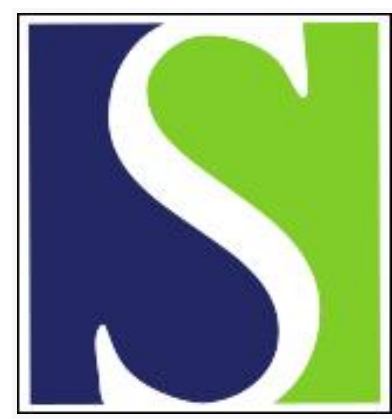

Scand J Work Environ Health 2009;35(6):461-465

https://doi.org/10.5271/sjweh.1362

Published online: 09 Oct 2009, Issue date: 00 Dec 2009

Fate of abstracts presented at an International Commission on Occupational Health (ICOH) congress - followed by publication in peer-reviewed journals?

by Rollin L, Darmoni S, Caillard J-F, Gehanno J-F

Affiliation: Service de médicine du travail, CHU de Rouen, 76000 Rouen, France. laetitia.rollin@chu-rouen.fr

Refers to the following text of the Journal: 2007;33(4):245-251

The following articles refer to this text: 2010;36(6):484-487;

2011;37(6):494-501

Key terms: abstract; bibliometrics; $\mathrm{ICOH}$; International Commission on Occupational Health; journal; peer review; peer-reviewed journal; publication; scientific meeting

This article in PubMed: www.ncbi.nlm.nih.gov/pubmed/19851699

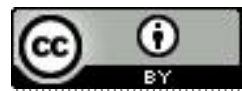




\title{
Fate of abstracts presented at an International Commission on Occupational Health (ICOH) congress - followed by publication in peer-reviewed journals?
}

\author{
by Laetitia Rollin, MD, ${ }^{1,2}$ Stefan Darmoni, MD, PhD, ${ }^{2}$ Jean-François Caillard, MD, PhD, ${ }^{2}$ Jean-François \\ Gehanno, $M D, P h D^{1,2}$
}

Rollin L, Darmoni S, Caillard J-F, Gehanno J-F. Fate of abstracts presented at an International Commission on Occupational Health (ICOH) congress - followed by publication in peer-reviewed journals? Scand J Work Environ Health. 2009;35(6):461-465.

\begin{abstract}
Objectives Presentations at international meetings offer an excellent way to disseminate current research findings. One measure of the quality of research is its subsequent publication. Our study aimed to determine the publication rate of abstracts presented at a congress of the International Commission on Occupational Health (ICOH), and to identify predictive factors of publication and differences between presented abstracts and subsequently published papers.

Methods We identified a random sample of 318 abstracts presented at the $2000 \mathrm{ICOH}$ meeting from the book of abstracts. Using Medline and Embase, we assessed their publication rate in the period ranging from 1998 to 2006 and investigated the factors associated with the publication rate.

Results Of 318 abstracts originating from 51 countries, 105 articles [33\%, 95\% confidence interval $(95 \% \mathrm{CI})$ 27-38)] were subsequently published in 67 journals indexed in Medline or Embase. Mean time to publication was 17 months (95\% CI 13-21). Multivariate analysis revealed that abstracts with quantitative data and written by authors originating from developed countries were significantly more published. From the time of abstract presentation to publication in a peer-reviewed journal, both the study sample size and the first author frequently changed ( $25 \%$ and $29 \%$, respectively), but the overall conclusions remained stable, except in one case.

Conclusions Most of the abstracts presented at the $2000 \mathrm{ICOH}$ congress were not subsequently published as full research reports. If this is the case for most abstracts submitted to conferences, this may limit the ability of a reader to judge the validity, reliability, and generalizability of the research presented. Caution is advised when referencing or generalizing from abstracts that have not been subsequently published in full.
\end{abstract}

Key terms bibliometrics; peer review; scientific meeting.

The point of scientific meetings is to allow people working in the same field of interest to meet, share ideas or concepts, and disseminate knowledge or new research findings. However, the validity of research presented during such events has been a matter of concern. Presentations are usually chosen on the basis of submitted abstracts, which may not contain sufficient information to assess the validity of the research (1, 2). It is often assumed that information contained in an abstract presentation will eventually be published in full manuscript form in a peer-reviewed journal as this validates the significance of the data and methods applied. Determining the rates of publication allows for an indirect measurement of the validity of results and conclusions of presentations at annual meetings. In a recent Cochrane Library review on full publication following the presentation of abstracts (3), 79 reports were identified and combined, which resulted in a weighted mean full publication rate of $44.5 \%$. Publication rates ranged from $8-81 \%$ differing both by meeting and specialty. Nevertheless, no study on the frequency of publication following abstract presentation exists for the field of occupational health.

The International Commission on Occupational Health (ICOH) hosts a renowned congress that takes place every three years and attracts thousands of occupational health

1 Institute of Occupational Health, Rouen University Hospital and University of Rouen, Rouen, France.

2 Computer and Networks Department LITIS EA 4108, Rouen University Hospital, Rouen, France.

Correspondence to: Dr Laetitia Rollin, Service de médicine du travail, CHU de Rouen, 1 rue de Germont, 76000 Rouen, France. [E-mail: laetitia.rollin@chu-rouen.fr] 
physicians. The objectives of our study were to assess: (i) the publication rate of abstracts presented at a single ICOH meeting, (ii) the predictive factors of publication, and (iii) the differences between abstracts accepted for presentation and those subsequently published.

\section{Methods}

\section{Study sample}

We randomly selected abstracts accepted for presentation at the $2000 \mathrm{ICOH}$ meeting in Singapore from the book of abstracts. Presentation formats included "oral presentations" and "posters presentations". We excluded "posters symposium". Our study looked at 25\% of abstracts presented at the congress (ie, 158 of 632 oral presentations and 160 of 641 posters).

\section{Assessment of subsequent publication}

We estimated the subsequent publication rate by scanning Medline on the PubMed server and Embase on Ovid (Ovid Technologies Inc, NY, USA) from 1 January, 1998 through 31 December, 2006. In searching for the abstracts, we initially combined the last name and first initial of the first author with a broad keyword in the title. If no corresponding paper was found, each subsequent author and the same keyword were used. If a corresponding paper was still not identified, another keyword culled from the title was used in combination with the names of all the authors, combined with the Boolean operator "OR". We considered a presented abstract as having been published if a corresponding abstract in title, study design, and one author name was identified in our search. When we confirmed a full publication, we recorded the journal's title, and month, and year of publication. All abstracts published in a printed journal in the months before the meeting, or during the same month that the meeting took place, were considered to have been published before the meeting.

\section{Assessment of predictive factors of publication}

We recorded the following variables from each abstract presented at the ICOH meeting: (i) presentation type (ie, oral versus poster presentation), (ii) indication in the abstract of quantitative data, (iii) category of occupational health risk, and (iv) country of origin of the first author. We used the author's country of origin to identify the official language, gross national income (GNI) per capita (with a threshold fixed at \$3000), and the continent. First authors originating from Canada, Australia, the UK, or USA were considered to be native English speakers.
Agreement between presented and published abstracts

When we identified a full publication, we verified the concordance between the results displayed in the abstract submitted to the meeting and those displayed in the abstract that was subsequently published.

\section{Data analysis}

First, we determined the rates of publication per year. Then, using the Pearson $\chi 2$ test and Fisher's exact test, we analyzed the association between the different variables recorded in the abstract presented at $\mathrm{ICOH}$ (ie, presentation type, country of origin of the first author, indication in the abstract of quantitative data, category of occupational health risk) and the successfully published paper. We calculated the odds ratios (OR) and their confidence intervals $(95 \% \mathrm{CI})$ with the $\alpha$ risk set at $5 \%$. We performed multivariate analysis, designed to test the independent effect of each of the factors associated with successful publication, using the logistic regression model; all statistical analyses were conducted with the STATA software program, version 9.0 (Statacorp LP, College Station, TX, USA).

\section{Results}

Of the 318 abstracts studied (158 oral presentations and 160 posters), 105 were subsequently published in journals indexed in Medline or Embase, resulting in a publication rate of $33 \%$ (95\% CI 27-38). The mean time to publication was 17 months (95\% CI 13-21). Nevertheless, 19 articles (18\% of the published abstracts) had already been published when the congress took place. Of the 86 abstracts published after the meeting, 28 (33\%) were published within one year, $53(62 \%)$ within two years, $75(87 \%)$ within four years and $86(100 \%)$ within six years (figure 1). Publications occurred in 67 different journals, of which 26 specialized in occupational medicine. These occupational health journals accounted for $57 \%$ of the published articles.

Abstracts presented at the $\mathrm{ICOH}$ meeting originated from 51 countries, mainly Europe (53\%) and Asia, including Japan (28\%), but those subsequently published originated from only 27 countries. A bivariate analysis of publication success (table 1) showed a positive association with: (i) the first author's continent of origin $(\mathrm{P}=0.01)$, (ii) his or her country of origin, (iii) the author's country of origin having GNI per capita higher than $\$ 3000$ $(\mathrm{P}<0.001)$, and (iv) results containing quantitative data $(\mathrm{P}<0.001)$. Publication success was unrelated to: (i) the presentation type, (ii) whether the first author originated from an English-speaking country, or (iii) the category of occupational risk dealt with in the abstract. 
The multivariate analysis (table 2) showed that factors associated with subsequent publication were: (i) the author's country of origin having GNI per capita higher than $\$ 3000$ (OR 7, $\mathrm{P}=0.003$ ) and (ii) results with quantitative data (OR 6.4, $\mathrm{P}<0.001)$. The factor "first author originating from English-speaking country" was nearly significant ( $\mathrm{OR} 2.2, \mathrm{P}=0.06)$. The type of presentation was not associated with success publication.

We noticed frequent changes between the abstract presented at $\mathrm{ICOH}$ and the abstract displayed in the full publication. The first author frequently changed (29\%) while the study sample size and numerical data were different in $25 \%$ cases, but the overall conclusions remained stable in all but one abstract.

\section{Discussion}

Overall, we found that a small percentage of abstracts presented at the ICOH conference were subsequently published. The ICOH meeting was chosen because it is considered to be the most important international general conference in the field of occupational health. We analyzed the 2000 meeting to take into consideration the possible long delay between a conference and subsequent publication observed in similar studies that focused on other specialties $(4,5,6)$.

We included 318 abstracts in our analysis, which is similar to the amount included in most of the studies published so far on this topic (3), and searched for a publication within six years following the conference. Previous studies have shown that the mean time for publication is approximately 18 months (3). Furthermore, in our study, among the abstracts published after the meeting took place, only $10 \%$ were published between four

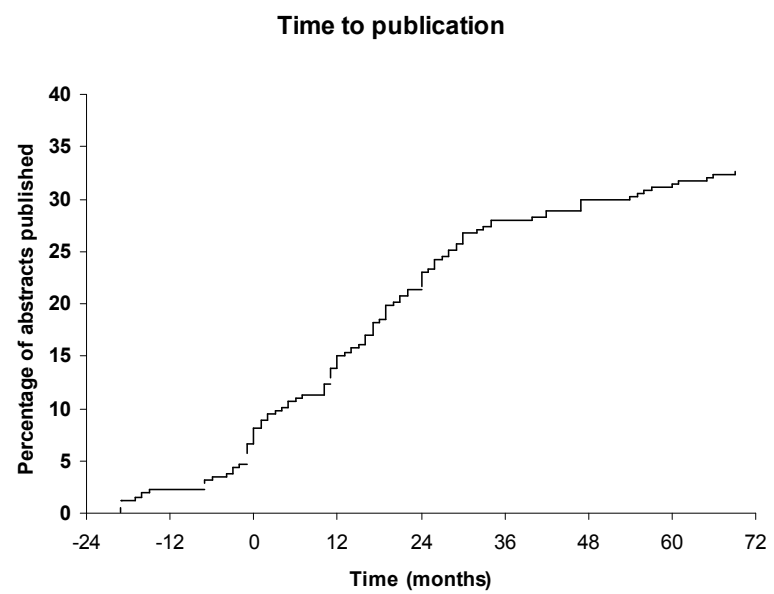

Figure 1. Time between the meeting and the subsequent publication of abstracts presented at the ICOH meeting (cumulated percentage).
Table 1. Factors related to publication status (bivariate analysis). ( $\mathrm{OR}=$ odds ratio; $95 \% \mathrm{Cl}=95 \%$ confidence interval)

\begin{tabular}{|c|c|c|c|c|c|c|c|}
\hline \multirow[t]{3}{*}{ Factor } & \multicolumn{4}{|c|}{ Publication status } & \multirow{3}{*}{$\begin{array}{c}\text { P- } \\
\text { value }^{\text {a }}\end{array}$} & \multirow[t]{3}{*}{ OR } & \multirow[t]{3}{*}{$95 \% \mathrm{Cl}$} \\
\hline & \multicolumn{2}{|c|}{ Published } & \multicolumn{2}{|c|}{ Unpublished } & & & \\
\hline & $\mathrm{N}$ & $\%$ & $\mathrm{~N}$ & $\%$ & & & \\
\hline \multicolumn{5}{|l|}{ Presentation type } & 0.45 & & \\
\hline Poster & 56 & 35 & 14 & 65 & . & 1.0 & .. \\
\hline Oral & 49 & 31 & 109 & 69 & · & 0.8 & $0.5-1.4$ \\
\hline \multicolumn{5}{|c|}{ Continent origin of the first author } & 0.01 & & \\
\hline North America & 7 & 37 & 12 & 63 & . & . & . \\
\hline South America & 2 & 18 & 9 & 82 & . & . & . \\
\hline Europe & 66 & 39 & 102 & 61 & . & . & · \\
\hline Asia (including & & & & & & & \\
\hline $\begin{array}{l}\text { Japan) } \\
\text { Russia and }\end{array}$ & 26 & 29 & 63 & 71 & $\cdot$ & $\cdot$ & · \\
\hline East Europe & 3 & 25 & 9 & 75 & . & $\cdot$ & - \\
\hline Africa & 0 & 0 & 16 & 100 & . & $\cdot$ & . \\
\hline Australia & 1 & 33 & 2 & 67 & · & · & . \\
\hline \multicolumn{5}{|c|}{$\begin{array}{l}\text { Author's country of origin having } \\
\text { gross national income per capita of }\end{array}$} & 0.001 & & \\
\hline$<\$ 3000$ & 3 & 7 & 37 & 93 & . & 1.0 & .. \\
\hline$>\$ 3000$ & 102 & 37 & 176 & 63 & $\cdot$ & 7.1 & $2.1-36.9$ \\
\hline \multicolumn{5}{|c|}{ Author from English-speaking countries } & 0.17 & & \\
\hline No & 91 & 32 & 195 & 68 & . & 1.0 & .. \\
\hline Yes & 18 & 56 & 14 & 44 & . & 1.7 & $0.7-3.7$ \\
\hline \multicolumn{5}{|c|}{ Results with quantitative data } & 0.001 & & \\
\hline No & 8 & 11 & 68 & 89 & . & 1.0 & .. \\
\hline Yes & 97 & 40 & 145 & 60 & $\cdot$ & 5.6 & $2.6-14.2$ \\
\hline \multicolumn{5}{|c|}{ Type of occupational risk } & 0.38 & & \\
\hline Biological & 2 & 33 & 4 & 67 & . & . & · \\
\hline Chemical & 47 & 38 & 75 & 62 & . & . & . \\
\hline Organizational & 12 & 36 & 21 & 64 & . & . & . \\
\hline $\begin{array}{l}\text { Physical } \\
\text { Specific }\end{array}$ & 20 & 34 & 38 & 66 & . & - & . \\
\hline occupations & 16 & 28 & 41 & 72 & . & . & · \\
\hline Not concerned & 8 & 19 & 34 & 81 & . & . & . \\
\hline
\end{tabular}

a Fisher's exact test.

Table 2. Multiple logistic regression of publication success. ( $\mathrm{OR}=$ odds ratio; $95 \% \mathrm{Cl}=95 \%$ confidence interval)

\begin{tabular}{|c|c|c|c|c|c|c|c|}
\hline \multirow[t]{3}{*}{ Factor } & \multicolumn{4}{|c|}{ Publication status } & \multirow{3}{*}{$\begin{array}{c}\mathrm{P}- \\
\text { value }\end{array}$} & \multirow[t]{3}{*}{$\mathrm{OR}$} & \multirow[t]{3}{*}{$95 \% \mathrm{Cl}$} \\
\hline & \multicolumn{2}{|c|}{ Published } & \multicolumn{2}{|c|}{ Unpublished } & & & \\
\hline & $\mathrm{N}$ & $\%$ & $\mathrm{~N}$ & $\%$ & & & \\
\hline \multicolumn{5}{|c|}{ Presentation type } & 0.27 & & \\
\hline Poster & 56 & 35 & 104 & 65 & . & 1.0 & .. \\
\hline Oral & 49 & 31 & 109 & 69 & . & 0.8 & $0.4-1.3$ \\
\hline \multicolumn{5}{|c|}{ Author from English-speaking countries } & 0.06 & & \\
\hline No & 91 & 32 & 195 & 68 & . & 1.0 & \\
\hline Yes & 18 & 56 & 14 & 44 & . & 2.2 & $0.9-5.2$ \\
\hline \multicolumn{5}{|c|}{$\begin{array}{l}\text { Author's country of origin having } \\
\text { gross national income per capita of }\end{array}$} & 0.003 & & \\
\hline$<\$ 3000$ & 3 & 7 & 37 & 93 & . & 1.0 & .. \\
\hline$>\$ 3000$ & 102 & 37 & 176 & 63 & . & 7.0 & $2.0-23.8$ \\
\hline \multicolumn{5}{|c|}{ Results with quantitative data } & $<0.001$ & & \\
\hline No & 8 & 11 & 68 & 89 & . & 1.0 & .. \\
\hline Yes & 97 & 40 & 145 & 60 & . & 6.4 & $2.8-14.4$ \\
\hline
\end{tabular}


to six years after the meeting, whereas $69 \%$ appeared within two years after the meeting. Increasing the period, would therefore probably not have significantly increased the percentage of published abstracts.

Since Medline and Embase are not exhaustive in the field of occupational medicine (7), the rate of publication observed in our study is probably an underestimation of the real rate. Nevertheless, most of the studies that tried to assess this rate in other disciplines used only Medline, since it is the most important and freely accessible medical database. (4-6)

Overall, one third of abstracts accepted at the conference were subsequently published. Although the publication rate can be considered as low, it is similar to the rate of publication observed in non-specialized congresses in other medical specialties (3). Usually, the rate of subsequent publication is higher for congresses dealing with specific research topics. $(3,8)$. This may reflect the fact that most people presenting in research meetings with a narrow subject are usually researchers and are more prone to publish their results in peer-reviewed journals.

The publication rate would drop to $27 \%$ if we considered only those abstracts that had not already been published at the time of the conference. It is worthy to note that six abstracts had been published more than one year before the beginning of the conference. Among the 86 abstracts published after the conference, five were published within three months. At the time of the conference, and probably at the time of submission of the abstract to the conference, the authors in fact knew their work was going to be published. Therefore, the idea that meetings allow participants to have access to research results in advance does not apply to $23 \%$ of abstracts that were published in peer-reviewed journals.

The reasons for such a low publication rate are multi-factorial. The ICOH meetings concern research and practice; all authors are not necessarily researchers. Some of them submit an abstract to have an official reason to attend the congress. Furthermore, some training programs pay for travel costs to national meetings for trainees who are presenting abstracts, which encourages trainees to prepare abstracts, but not full manuscripts. These observations confirm previous findings that publication in a scientific journal is not the ultimate goal of every abstract presentation (6). When Sprague et al (9) surveyed the authors of unpublished orthopedic abstracts five years after a specific meeting, about 36\% of respondents had not submitted their abstract for publication. Their reasons for failure to submit included (i) insufficient research material available, (ii) the research was still in progress, (iii) procrastination in writing the manuscript, (iv) difficulties with co-authors, and (vi) the topic was not a research priority.

Due to the marked differences in the peer-review process for a paper to be, on the one hand, presented at a scientific meeting and, on the other hand, published in an indexed journal, many abstracts accepted for presentation at a conference would fail to withstand the rigorous peer-review process of a journal (10). For example, among the abstracts presented at an orthopedic meeting and not subsequently published, $27 \%$ had in fact been submitted to a journal for publication, but been rejected (9).

Moreover, some researchers submit abstracts with data coming from subgroups or small populations, and these results are hard to identify in subsequent publications. In our study, we had several examples of such a situation, involving mostly big research groups.

Multivariate analysis demonstrated that the only significant factors predicting subsequent publication were (i) results with quantitative data and (ii) first author's country of origin having a GNI per capita higher than $\$ 3000$. Originating from an English-speaking country was nearly significant. Possible influences included the relationships between language proficiency and publication, since most scientific journals are published in English. It could also be possible that full publication of abstracts from non-western countries may be higher in journals that are not indexed in Medline or Embase, such as regional journals. In contrast to previous studies (3), we did not observe that results presented orally are more likely to be subsequently published than those presented in a poster session $(\mathrm{P}=0.27)$.

Interestingly, among the 318 abstracts included in our study, more than half (53\%) came from Europe. The second most important contributor was Asia (including Japan) and, only in third place, North America. The fact that the congress took place in Asia could explain the number of abstracts originating from this part of the world, but Europe's prominence may reflect the importance of occupational medicine research in Europe (11) or the decline of such research in the US (12). The Fisher's exact test showed significant differences between the publication rate of continents, mainly due to the lack publication of abstracts originating from Africa. Although 16 abstracts - out of the 318 included in our study - came from Africa, none were subsequently published in a peer-reviewed journal. This may be an illustration of the fact that research originating from this continent does not appear in international bibliographic databases (13).

The overall conclusions remained stable between presented and published abstracts, except in one case in which the conclusion was the opposite. Nevertheless, in several cases, we observed differences in the data mentioned in the presented abstract, as compared to those displayed in the published abstract. The study sample size and numerical data were different in $25 \%$ of cases, with the former usually being larger in the published abstract. This could be due to the fact that studies 
presented at congresses may be ongoing studies and, therefore, the results presented are only preliminary.

Authorship is an explicit way of assigning responsibility and giving credit for intellectual work. Many different ways of determining order of authorship exist across disciplines, research groups, and countries. The most prevalent authorship policy includes descending order of contribution, placing first the person who took the lead in writing the manuscript or doing the research. The first author should therefore be the same in both the presented abstract and the published manuscript, even if the results submitted to the conference are only preliminary results. Nevertheless, we observed that the first author frequently changed (29\%) between the conference and publication. We have no explanation for this but we suspect that this could be part of the ongoing debate on honorary and ghost authorship - authors are sometimes granted authorship even if they played no significant role in the work (honorary authorship) while others are not listed although their contribution to the work may have been important (ghost authorship).

\section{Concluding remarks}

Overall, two thirds of the abstracts presented at the $\mathrm{ICOH}$ conference were not subsequently published in peerreviewed journals. This calls into question the practice of using information gained at the international meetings of occupational medicine in clinical practice, particularly in this era of evidence-based medicine. People attending meetings must be aware of this important limitation before using the material they get from the conferences. At the same time, the research community could try to improve the quality of the studies presented, by establishing stricter guidelines to limit the presentation of flawed or preliminary data at international meetings.

Nevertheless, the methodological quality of a study or a report is difficult to evaluate on the basis of a single abstract; selecting material to be presented in meetings on this basis inevitably yields to very variable quality. Yet, applying strict criteria (eg, asking for a full manuscript instead of an abstract) would discourage most practitioners from attending the meetings, which allow them to share their experience and, hopefully, lead to an improvement in clinical practice. Furthermore, bringing researchers and practitioners together to debate may generate new research hypotheses and promote international collaboration. This could warrant further investigation.

\section{Acknowledgements}

The authors thank Richard Medeiros, Rouen University Hospital Medical Editor for editing the manuscript and
Jean-François Ménard and Joel Ladner for their help in the statistical analyses. We also thank Ovid for having provided free access to the Embase database for this study.

\section{References}

1. Relman AS. News reports of medical meetings: how reliable are abstracts? N Engl J Med. 1980;303:277-8.

2. Froom P, Froom J. Deficiencies in structured medical abstracts. J Clin Epidemiol. 1993;46:591-4.

3. Scherer RW, Langenberg P, von Elm E. Full publication of results initially presented in abstracts. Cochrane Database Syst Rev. 2007;2:MR000005.

4. Carroll AE, Sox CM, Tarini BA, Ringold S, Christakis DA. Does presentation format at the Pediatric Academic Societies' annual meeting predict subsequent publication? Pediatrics. 2003;112:1238-41.

5. Peng PH, Wasserman JM, Rosenfeld RM. Factors influencing publication of abstracts presented at the AAO-HNS Annual Meeting. Otolaryngol Head Neck Surg. 2006;135:197-203.

6. Autorino R, Quarto G, Di Lorenzo G, De Sio M, Damiano R. Are abstracts presented at the EAU meeting followed by publication in peer-reviewed journals?: a critical analysis. Eur Urol. 2007;51:833-40.

7. Gehanno JF, Paris C, Thirion B, Caillard JF. Assessment of bibliographic databases performance in information retrieval for occupational and environmental toxicology. Occup Environ Med. 1998;55:562-6.

8. Von Elm E, Costanza MC, Walder B, Tramèr MR. More insight into the fate of biomedical meeting abstracts: a systematic review. BMC Med Res Methodol. 2003;3:12.

9. Sprague S, Bhandari M, Deveraux PJ, Swiontkowski MF, Tornetta P 3rd, Dook DJ, et al. Barriers to full-text publication following presentation of abstracts at annual orthopaedic meetings. J Bone Joint Surg Am. 2003;85:158-63.

10. Rubin HR, Redelmeier DA, Wu AW, Steinberg EP. How reliable is peer review of scientific abstracts?: looking back at the 1991 annual meeting of the Society of General Internal Medicine. J Gen Intern Med. 1993;8:255-8.

11. Gehanno J-F, Takahashi K, Darmoni S, Weber J. Citation classics in occupational medicine journals. Scand J Work Environ Health. 2007;33(4):245-51.

12. LaDou J. The rise and fall of occupational medicine in the United States. Am J Prev Med. 2002;22:285-95.

13. Hofman KJ, Kanyengo CW, Rapp BA, Kotzin S. Mapping the health research landscape in Sub-Saharan Africa: a study of trends in biomedical publications. J Med Libr Assoc. 2009;97:41-4.

Received for publication: 27 March 2009 